\title{
AVALIAÇÃO DO EFEITO DA PELETIZAÇÃo SOBRE O VIGOR DE SEMENTES DE ALFACE (Lactuca sativa $\mathbf{L}$.)
}

\author{
H.M. CORASPE \\ Fondo Nacional de Investigaciones Agropecuarias-FONAIAP. Estación Experimental Trujillo, Valera, C.P. 269, \\ Trujillo. Venezuela. \\ H. GONZALES IDIARTE \\ Facultad de Agronomia, 12.900 - Garzon 780 - Montevideo, Uruguay. \\ K. MINAMI \\ Departamento de Horticultura da ESALQ/USP, C.P. 9, CEP:13418-900 - Piracicaba,SP. Brasil.
}

\begin{abstract}
RESUMO: Sementes de alface (Lactuca sativa L.) cv. Verônica, do tipo crespo, foram submetidas a testes de umidade, germinação, velocidade de germinaçāo, envelhecimento acelerado, teste de frio, condutividade elétrica, e emergência. Os testes de laboratório não evidenciaram diferenças significativas da qualidade fisiológica entre sementes peletizadas e sem paletes, exceto o teste de envelhecimento acelerado. As correlaçōes entre os testes de laboratório e a emergência em campo não foram significativas. A emergência em campo foi significativamente maior nas sementes peletizadas.
\end{abstract}

Descritores: alface, Lactuca sativa $L$., paletes, vigor das sementes.

\section{EVALUATION OF THE PELLETIZATION EFFECT ON LETTUCE SEED VIGOR (Lactuca sativa L.)}

\begin{abstract}
ARSTRACT: Seeds of "Veronica", a crisphead lettuce cultivar (Lactuca sativa L.), were submitted to laboratory tests of humidity, germination, velocity of germination, accelerated aging, cold, electrical conductivity and field emergence. Tests did not show any significant difference of the physiological quality between bare and pelleted seeds, except the accelerated aging. Correlations among laboratory tests and the field emergence were not significant. The field emergence was significantly higher from pelleted seeds than seeds without pellets.
\end{abstract}

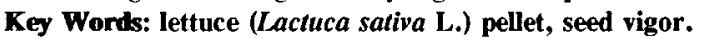

\section{INTRODUÇÃO}

As sementes peletizadas são usadas na produção de certas hortaliças e plantas ornamentais. A disponibilidade de sementes revestidas tem contribuido para o desenvolvimento da semeadura com precisão.

Para MILLIER \& SOOTER (1967), a semeadura de precisão é a colocação de uma ou mais sementes no solo, numa profundidade $\mathrm{e}$ espaçamento determinado, com cobertura uniforme e a uma velocidade razoável. Esta operação traz vantagens inegáveis, como a redução ou eliminação do desbaste, maior uniformidade na maturação, populações determinadas de plantas e economia de sementes. Tudo isto leva a uma diminuição de custos de produção e incremento do rendimento $\mathrm{e}$ qualidade da colheita. Para efetuar a semeadura de precisão é necessário classificar as sementes, antes de colocá-las no solo, mas, este processo de classificação é dificultado no caso de algumas sementes de hortaliças, como alface, as quais são pequenas, com baixa densidade e de forma irregular. $O$ uso de sementes peletizadas, de certa forma, tem resolvido estes inconvenientes.

Alguns problemas, entretanto, relatados pelo uso de semente peletizada comparada com o uso de semente sem paletes, referem-se à menor emergência total de plântulas, decrescimo da taxa de emergência e a presença de plântulas anormais (MILLIER \& SOOTER, 1967).

Bishop (1946), citado por MILLIER \& SOOTER (1967), encontrou em testes de germinação em laboratórios, percentagem de germinação maior em sementes não peletizadas de cebola e alface, porém nenhum efeito de danos foi observado em sementes, após a remoção dos paletes.

McCOY et al. (1969) afirmaram que normalmente é plantado entre 24 a 50 vezes mais sementes de alface que a quantidade necessária, para assegurar a população adequada de plantas. 
Isto leva a altos custos de mão-de-obra para fazer o desbaste. A semeadura de precisão permitiria baixar os custos por desbaste. Os autores compararam sementes peletizados e sem peletizar, sob dois sistemas de irrigação (aspersão e por sulcos). O resultado achado é que a semente peletizada deu uma menor população de plantas que a não peletizada.

$O$ revestimento com argila de sementes peletizadas reduz a quantidade de oxigênio reduzindo a germinação da semente. Aumentando-se $o$ nível de $\mathrm{O}_{2}$ na atmosfera, ao redor da semente, há incremento na emergência de plântulas (MILLIER \& SOOTER, 1967).

Em pimentão (Capsicum annuum L.) resultados similares foram obtidos por SACHS et al. (1981), comprovando o efeito inibitório do revestimento da semente. A causa dessa inibição foi devido à limitação da disponibilidade de $\mathrm{O}_{2}$ da semente, atuando o pelet como uma barreira mecânica.

ROOS \& MOORE (1975) consideram que as vantagens da semente peletizada são:

a) semeadura de precisão em sementes pequenas e irregulares;

b) menores custos de desbate;

c) menores estresses por desbaste;

d) microambiente da semente mais uniforme;

e) possibilidade de incluir produtos químicos;

f) uso de menor quantidade de semente;

g) maior facilidade de manuseio na semeaduras a mão.

Miller \& Bensin (1974), citados por ROOS \& MOORE (1975), salientam que a semente peletizada comporta-se diferentemente, segundo as propriedades hidrofilicas ou hidrofóbicas do material usado e do conteúdo de água do solo.

ROOS \& MOORE (1975) também estabeleceram que alguns problemas da semente peletizada ainda devem ser resolvidos, como por exemplo: composição de material para condições específicas do solo; manejo e armazenamento da semente peletizada; desenvolvimento de procedimentos padrões de germinação para este tipo de semente; fabricação de semeadeiras especializadas.

CHRIMES \& GRAY (1982) compararam semente de alface pré-germinada (PG), seca (S) e peletizada(P). A PG deu entre $1-6 \%$ mais emergência que a $P$ e entre $1-3 \%$ mais que a $S$. OS autores concluiram que os resultados obtidos mostram que é possível estabelecer satisfatoriamente cultivos de alface, mediante a semeadura de semente pré-germinada em bandejas, em vez da peletizada.

ROBINSON et al. (1983) compararam 7 materiais diferentes, usados para peletizar sementes de alface em um amplo gradiente de textura do solo, temperaturas e cultivares. Encontraram que três desses materiais tiveram uma taxa de emergência mais rápida que os resultantes. Os autores comentam que para as condições do Imperial Valley, na Califórnia, cada dia de redução do período de emergência representa um decréscimo de US $\$ 139.500$, nos 16.200 ha de alface plantadas (que são irrigados por aspersão até a emergência). Em geral a qualidade fisiológica é indicada por testes de germinação e testes de vigor, feitos em laboratórios. O teste de germinação avalia a qualidade dos lotes que são comercializados para a semeadura.

Este teste é feito em condições ótimas, o que permite a manifestação do máximo potencial de germinação (BRASIL, 1980). Porém, no campo, as percentagens de emergência são geralmente menores que aquelas obtidas em testes de germinação, porque as sementes ficam sujeitas a uma série de condições adversas.

Em razão disso, têm sido desenvolvidos diversos testes de vigor para estimar com mais precisão o desempenho das sementes no campo.

As pesquisas para ajustar os procedimentos desses testes têm sido direcionadas principalmente para sementes de grandes culturas (PERRY, 1981; YAKLICH \& KULIK, 1979; GRABE, 1978).

Para espécies olerícolas, têm-se realizado poucas pesquisas em relação a metodologias adequadas para avaliar o vigor das sementes.

Os objetivos do presente trabalho foram avaliar a qualidade fisiológica da semente de alface (cv. Verônica) peletizada e sem paletes; e conferir a eficácia relativa de diferentes métodos de laboratório utilizados para analisar o vigor da semente, em relação à emergência em campo.

\section{MATERIAL E MÉTODOS}

O trabalho foi conduzido no Laboratório de sementes e no campo experimental do Departamento de Horticultura da ESALQ (USP), no período de setembro a dezembro de 1992. Usou-se um mesmo lote de sementes da cultivar Verônica, com e sem paletes. 

seguintes:

As análises de laboratório foram as

Grau de umidade da semente: foi determinado pelo método de estufa a $10 \pm 3^{\circ} \mathrm{C}$ durante $24 \mathrm{hs}$, com 2 repetições, de acordo com as Regras para Análise de Sementes (BRASIL, 1980).

Teste de germinação: utilizou-se 200 sementes para cada tratamento (4 repetições de 50 sementes por repetição). Cada repetição colocou-se em uma caixa gerbox, com as sementes sobre duas folhas de papel germibox. A quantidade de água acrescentada foi igual ao peso do papel seco multiplicado por 2,3 . O teste de germinação foi conduzido segundo as RAS, com $18-19^{\circ} \mathrm{C}$ de temperatura e luz. A contagem foi feita aos 7 dias. Também foi realizada uma contagem de emissão de radícula ao $2^{\circ}$ e $3^{\circ}$ dia, iniciado o teste.

Velocidade de germinação: foi realizada conjuntamente com o teste de germinação. Entre os dias 1 e 7 , contou-se diariamente as plântulas normais, as quais foram removidas do substrato. Ao fim do teste, determinou-se um índice de vigor através da somatória do número de plântulas germinadas em cada dia, dividida pelo número de dias decorridos entre a semeadura $\mathbf{e}$ a emergência. Maior índice, maior vigor.

Envelhecimento acelerado: utilizou-se caixa gerbox como mini-câmaras, possuindo em seu interior uma bandeja de tela padrão e outra colocada acima com furos menores, já que a semente de alface passa através da bandeja padrão, e adicionando $40 \mathrm{ml}$ de água. Uma vez colocadas as sementes, tampou-se para serem levadas a um germinador. Aí permaneceu 72 hs a $42^{\circ} \mathrm{C}$ e $100 \%$ UR (MARCOS FILHO et al. 1987). Após esse tempo, as amostras foram colocadas para germinar segundo as RAS (BRASIL, 1980). A interpretação segue os critérios estabelecidos pelas RAS, para o teste de germinação, com contagem aos 7 dias. Utilizou-se para cada tratamento 4 repetições de 50 sementes cada.

Teste de frio: para a execução do teste misturou-se areia e solo não esterelizado na proporção $2: 1$. A mistura foi colocada em caixa gerbox, ajustando-se a umidade a $60 \%$ da capacidade e campo. Após a semeadura (50 sementes por recipiente) e ter acrescentado água, as caixas foram fechadas e colocadas em câmara fria $\left(10^{\circ} \mathrm{C}\right.$ por 7 dias $)$. Vencido esse período, as caixas foram colocadas a temperatura ambiente, fazendo-se a contagem de plântulas normais nesse mesmo dia, aos 4 e 6 dias após. Observou-se que ao tirar as caixas da câmara fria, a maioria das sementes já estava germinada.

Condutividade elétrica: usou-se 4 repetições de 50 sementes para cada tratamento. Antes de começar - teste, houve necessidade de se aumentar a percentagem de umidade das sementes, pois, a umidade inicial era muito baixa, ṇão estando dentro dos limites de 12 e $17 \%$ (ASSOCIATION OF OFFICIAL SEED ANALYSIS, 1983). Primeiro tentou-se aumentar a umidade colocando a semente em câmara a $15^{\circ} \mathrm{C}$ e alta UR. Como não logrou-se chegar nos valores desejados, colocou-se as sementes em caixas gerbox usadas para envelhecimento acelerado, acima de uma tela e com $40 \mathrm{ml}$ de água no fundo. As caixas tampadas foram colocadas em câmaras germinadoras, a $20^{\circ} \mathrm{C}$ por um dia para aumentar a umidade. Após esta preparação das sementes, fez-se a contagem de $\mathbf{5 0}$ sementes por repetição e, pesando-as (precisão de $0,01 \mathrm{~g}$ ) e colocaram-nas em copos de plástico com $25 \mathrm{ml}$ de água destilada. As sementes assim imersas permaneceram no germinador a $20^{\circ} \mathrm{C}$ durante 24 horas. Ao término deste período, as sementes estiveram germinadas, o que impediu fazer o teste de condutividade.

Emergência a campo: usaram-se canteiros ao ar livre. Em cada sulco, colocou-se as sementes, semeadas manualmente separadas a $1 \mathrm{~cm}$ entre si. Cada parcela esteve composta por dois sulcos (100 sementes). A semeadura foi feita no dia 10/11/92 e as leituras foram feitas entre os dias 17 e 20, até a emergência se estabilizar. Anotou-se o número de plântulas emergidas normais. A irrigação foi feita duas vezes por dia, observando-se alguns problemas na distribuição da água.

O delineamento estatístico usado foi parcelas inteiramente casualizadas, com 4 repetições.

Os resultados de cada teste foram analisados estatisticamente através da análise de variância e as médias foram comparadas pelo teste de Tukey.

Calcularam-se as correlações simples entre cada teste de laboratório e a emergência a campo. 


\section{RESULTADOS E DISCUSSÃO}

As sementes utilizadas nos experimentos apresentaram conteúdo de umidade de $3,1 \%$ nas sementes peletizadas e $5,4 \%$ para as sementes sem paletes. Estes valores, principalmente o de 3,1\%, são considerados muito baixos para os requerimentos de experimentação, desconhecendose até que ponto o palete interferiu nos cálculos de umidade e os efeitos dessa umidade nos resultados.

Por exemplo, ROOS \& MOORE (1975) adaptaram o critério de tirar previamente o palete que reveste a semente para fazer o teste de germinação. Também estabelecem que é necessário desenvolver testes padrões de germinação para a semente peletizada.

Pode-se afirmar que os testes de laboratório não evidenciaram diferenças significativas da qualidade fisiológica entre sementes peletizadas e sem palete, exceto o teste de envelhecimento artificial (TABELA 1). A emergência em campo apresentou diferenças significativas, sendo maior para o tratamento de sementes peletizadas.

Os valores encontrados no teste de envelhecimento artificial, embora significativos foram opostos aos achados em emergência em campo, isto é, a semente peletizada mostrou baixa percentagem no teste, enquanto altos valores no campo. As plântulas anormais das sementes peletizadas neste teste caracterizaram-se por não apresentarem radiculas ou estarem atrofiadas. Por outra parte, as sementes peletizadas tiveram percentagem de umidade menor do que as sementes sem paletes $(3,1 \%$ e $5,4 \%$ respectivamente), observando-se um comportamento contrário ao apontado por MARCOS FILHO et al. (1987), segundo eles, as sementes mais úmidas apresentam atividade metabólica intensificada a altas temperaturas. Então, fatores não suficientemente claros, como o efeito do palete sobre a semente neste teste, ou aeração podem ter influenciados.

O teste de frio foi efetuado de acordo com as especificações gerais (MARCOS FILHO et al., 1987), porém, observou-se que após o período de 7 dias a $10^{\circ} \mathrm{C}$ a câmara, as sementes tinham germinado, evidenciando que a temperatura usada não foi estressante. E conveniente desenvolver trabalhos de pesquisa que permitam conhecer com exatidão as temperaturas e o tempo necessário para executar este tipo de teste em alface.

Para efetuar o teste de condutividade elétrica foi preciso aumentar o conteúdo de umidade nas sementes. Estes tratamentos além de não proporcionarem a umidade mínima requerida causaram a germinação das sementes, impedindo de fazer o teste. Faz-se necessário aferir este teste para sementes de alface.

Os coeficientes de correlação dos testes de vigor em laboratório e a emergência em campo não mostraram significância (TABELA 2). Porém, observa-se nos testes de frio, velocidade de emergência e contagem de emissão de radícula, uma tendência similar ao que foi obtido em campo. (TABELA 1).

O experimento em campo está sujeito a fatores ambientais os quais são de difícil controle e podem ter grande influência nos resultados. Há necessidade de estabelecer procedimentos padrões e uniformizar certas variáveis, como distribuição de água, umidade e temperatura do solo. Neste caso, o fator de maior perturbação em campo foi a distribuição de água, provavelmente.

A maioria da bibliografia consultada estabelece que a semente peletizada tem um pior comportamento no campo que a semente sem palete, embora em alguns casos esta diferença seja muito pequena (ROOS \& MOORE, 1975; McCOY et al., 1969, CHRIMES \& GRAY, 1982; MILLIER \& SOOTER, 1927). ROOS \& MOORE (1975) manifestaram que é necessário resolver alguns problemas da semente peletizada para melhorar seu desempenho. Neste sentido, ROBINSON et al. (1983) conferiram que houve diferenças no desempenho de sementes peletizadas cobertas com 7 materiais diferentes.

Em nosso caso, as sementes peletizadas tiveram maior percentagem de emergência de plântulas no campo que as sem paletes. Esta diferença não foi encontrada nos testes feitos no laboratório.

Baseado no desconhecimento do material usado para fazer o palete, problemas na distribuição de água no experimento a campo e na necessidade de ajustar a metodologia de alguns testes de vigor para alface, seria de alto interesse poder continuar com esta linha de pesquisa devido a crescente difusão da semente peletizada de alface no Brasil. 
TABELA 1 - Valores obtidos nos testes de laboratório e de campo em sementes de alface cv. Verônica sem palete e peletizadas.

\begin{tabular}{cccccccc}
\hline \hline & $\begin{array}{c}\text { Umidade } \\
\text { da semente }\end{array}$ & $\begin{array}{c}\text { Teste de } \\
\text { germinação }\end{array}$ & $\begin{array}{c}\text { Envelhecimento } \\
\text { artificial }\end{array}$ & $\begin{array}{c}\text { Teste } \\
\text { de frio }\end{array}$ & $\begin{array}{c}\text { Emissão } \\
\text { de } \\
\text { radícula }\end{array}$ & $\begin{array}{c}\text { Velocidade } \\
\text { de } \\
\text { germinação }\end{array}$ & $\begin{array}{c}\text { Emergência } \\
\text { em campos }\end{array}$ \\
Tratamento & $(\%)$ & $(\%)$ & $(\%)$ & $(\%)$ & $(\%)$ & $(\%)$ & $(\%)$ \\
\hline sem palete & 5,4 & $99,00 \mathrm{a}$ & $94,00 \mathrm{a}$ & $93,75 \mathrm{a}$ & $93,50 \mathrm{a}$ & $9,3150 \mathrm{a}$ & $60,50 \mathrm{~b}$ \\
peletizada & 3,1 & $93,50 \mathrm{a}$ & $57,00 \mathrm{~b}$ & $95,00 \mathrm{a}$ & $99,50 \mathrm{a}$ & $10,0825 \mathrm{a}$ & $82,00 \mathrm{a}$ \\
\hline CV\% & & 3,77 & 6,75 & 5,09 & 5,70 & 16,19 & 13,79 \\
\hline \hline
\end{tabular}

Médias seguidas da mesma letra nas colunas não diferem estatisticamente pelo teste de Tukey ao nível de $5 \%$ de probabilidade.

TABELA 2 - Coeficiente de correlação simples (r) entre dados obtidos em teste de laboratório e a emergência em campo para sementes de alface cv. Verônica.

Germinação x Emergência em campo $0,0650 \mathrm{~ns}$

Envelhecimento Artificial $x$

Emergência em campo $\quad 0,3327$ ns

Teste de frio

$x$ Emergência em campo $\quad-0,4361 \mathrm{~ns}$

Emissão de radícula

$x$ Emergência em campo $\quad-0,1940$ ns

Velocidade de germinação

$x$ Emergência em campo $\quad 0,5099$ ns

$\mathrm{ns}=$ não significativo a $1 \%$ de probabilidade.

\section{CONCLUSÕES}

Os testes de laboratório não evidenciam diferenças significativas da qualidade fisiológica, entre sementes de alface sem paletes e peletizadas, exceto o teste de envelhecimento artificial.

Os valores do teste de envelhecimento artificial são contrários aos encontrados na emergência em campo. Fatores não devidamente entendidos devem estar incidindo nestes resultados obtidos.

A emergência em campo é significativamente maior nas sementes peletizadas.

As correlações entre os testes de laboratórios e a emergência em campo não são significativas.

Nos testes de frio e da condutividade elétrica, as metodologias recomendadas para outras espécies não se adaptam para a alface.

\section{AGRADECIMENTOS}

Os autores agradecem ao Laboratório de Análise de Sementes da ESALQ/USP, nas pessoas de Ana Dionísia L. Coelho Novembre e Helena Maria C. Pescarin Chamma pelo fornecimento dos equipamentos e valiosos conselhos, e à empresa AGROFLORA S/A Reflorestamento e Agropecuária pela doação da semente.

\section{REFERENCIA BIBLIOGRÁFICAS}

ASSOCIATION OF OFFICIAL SEED ANALYSIS Seed Vigour testing handbook. Springfield, 1983. 88p.

BRASIL. Ministério da Agricultura. Regras para análise de sementes. Brasîia, 1980. $188 \mathrm{p}$.

CHRIMES, J.R. e GRAY, D. Comparisons of the use of pre-germinated, dry and pelleted seeds for block-raising of glasshouse lettuce. Scientia Horticulturae, Amsterdan, v.17, n.1, p.15-25, 1982. 
GRABE, D.F. Measurement of seed vigor. Journal of seed Techmology. Springfield, v.1, n.12, p.18-31, 1976.

MARCOS FILHO, J.; CICERO, S.M.; SILVA, W.R. Avaliação da qualidade das sementes. Piracicaba, FEALQ, 1987. $230 \mathrm{p}$.

McCOY, O.D.; ROBINSON, F.E.; JONHSON, H.; CURLEY, R.G.; BROOKS, C.; GIANNINI, G.; LEBARON, F. Precision planting of lettuce. Journal of the America Society for Horticultural Science, Alexandria, v.94, n.4, p.344-345, 1969.

MILLIER, W.F.; SOOTER, C. Improving emergence of pelleted vegetable seed. Transactions of the ASAE, St. Joseph, v.10, n.5, p.658-666, 1967.

PERRY, D.A. Introduction, methodology and application of vigour test, seedling growth and evaluation teste. In: PERRY, D.A. (Ed.) Handbook of vigour teste methods. Zurich, International Seed Testing Association, 1981 p. p-20.
ROBINSON, F.E.; MAYBERRY, K.S.; SCHERER, D.J. Lettuce stand establishment with improved seed peletts. Transactions of the ASAE, St. Joseph, v.26, n.1, p.79-80, 1983.

ROOS, E.E.; MOORE, F.D. Effect of seed coating on performance of lettuce seeds in greenhouse soil tests. Journal of the American Society for Horticultural Science, Alexandria, v.100, n.5, p.573-576, 1975.

SACHS, M.; CANTLIFFE, D.J.; NELL, T.A. Germination studies of clay-coated sweet pepper seeds. Journal of the American Society for Horticultural Science, Alexandria, v.106, n.3, p.385-389, 1981.

YAKLICH, R.W.; KULIK, M.M. Evaluation of vigor tests in soybean seeds: relationship of the standard germination test, seedling vigor classification, seedling lenght, and tetrazolium staining, to field performance. Crop Science, Madison, v.19, n.2, p.247-252, 1979.

Enviado para publicação em 14.04.93 Aceito para publicação em 14.06 .93 